\title{
Pathogenesis and treatment of recurrent erosion
}

\author{
ROBERT WILLIAMS AND ROGER J BUCKLEY \\ From Moorfields Eye Hospital, City Road, London EC1V 2PD
}

SUMMARY A series of recurrent corneal erosions secondary to map-dot-fingerprint dystrophy is presented. Erosions were closely related to the Hudson-Stahli line, and this may be a factor in pathogenesis. Traumatic abrasions did not demonstrate such localisation, evidence that trauma is not a primary cause. A trial of management with therapeutic contact lenses versus topical medication was performed. Therapeutic contact lenses were shown to be inferior and had a high complication rate. Recurrent erosion is often considered an indication for therapeutic contact lenses, but this is questioned and great caution recommended in such use.

This paper presents the results of a prospective study on the pathogenesis and treatment of recurrent corneal erosion secondary to map-dot-fingerprint (MDF) corneal epithelial dystrophy. Additional observations are made on the site of erosion, its relationship to the Hudson-Stahli line, and the specular microscopic appearances of the underlying endothelium. There are further observations on the relationship to trauma. The results of the first comparative trial of therapeutic contact lenses in this condition are reported.

Recurrent corneal ulceration may occur in many conditions. ${ }^{1}$ In this paper the term recurrent erosion is confined to the epithelial loss that may occur in MDF dystrophy. This distinction is considered important, as MDF dystrophy is the commonest cause of recurrent erosion in general ophthalmic practice. The symptom complex is unlike other causes of ulceration, and the clinical and pathological findings are distinct. ${ }^{2}$

Recurrent erosion in MDF dystrophy may be a cause of great distress. The spontaneous attacks of severe pain, sometimes awakening the patient from sleep or on opening the eyelids, with associated epiphora, photophobia, and blurring of vision, may disrupt daily life. During an attack epithelial loss is seen with either small punctate erosions or loss of large areas of epithelium. ${ }^{3}$ Between attacks distinctive epithelial abnormalities described as map-dotfingerprint changes are seen on retroillumination. Fine refractile lines often in a whorl-like pattern resemble fingerprints or maps. ${ }^{4}$ The grey or white

Correspondence to Mr R Williams, FRCS. dots are epithelial microcysts. ${ }^{5}$ These changes may coexist and fluctuate. ${ }^{6}$

Possible aetiological factors are an inherited epithelial dystrophy, ${ }^{7}$ an age-related epithelial abnormality, ${ }^{8}$ and trauma. ${ }^{9}$ The frequent pathological finding of epithelial oedema ${ }^{10}$ may be secondary to endothelial dysfunction or tear film abnormality. Contact lenses have been implicated in one case."

A plethora of methods to prevent erosion has been proposed. These include topical lubricating agents, ${ }^{2}$ topical desiccating agents, ${ }^{12}$ topical steroids, ${ }^{13}$ debridement,${ }^{214}$ superficial keratectomy,${ }^{15}$ and therapeutic contact lenses. ${ }^{16}{ }^{17}$ Assessment of these treatments is difficult because there are no reports of a randomised trial or of the untreated natural history.

\section{Patients and methods}

Patients with recurrent erosion presenting to the Casualty Department at Moorfields Eye Hospital, London, between April and June 1983 were considered. The criteria for inclusion were a history of two or more previous occurrences (the patient having been seen on at least one occasion with epithelial loss), visible signs of MDF dystrophy in the same eye between episodes of erosion, no previous treatment other than topical medication, and no history of contact lens wear.

Details of age, sex, any history of trauma, and previous ocular or medical disease were recorded for each patient. The dates of the original symptoms and the number of recurrences were recorded. The symptom of pain was divided into three character- 
istics - frequency, duration, and severity - and each was graded on a scale of 1 to 4 . At presentation and again when the epithelium had healed the corneal appearance was recorded on a standardised proforma. The site and size of epithelial lesions were assessed by a specially prepared scale placed over the proforma.

A random selection of 10 patients was studied by endothelial specular photomicroscopy. The site underlying the previous erosion was examined with the contact specular microscope and recorded on monochrome film. Photographs were reported on by an independent observer with no clinical knowledge of the patients.

Patients were alternately and thus randomly ascribed to one of two treatment groups. Those in the first group were given gutt. hypromellose four times a day and oculentum simplex nightly. They were reviewed at two, four, and eight weeks. Those in the second had keratometry and were fitted with a suitable radius of curvature $14 \mathrm{~mm}$ diameter Duragel 75 plano therapeutic contact lens. If after 1 and 24 hours the lens fit was satisfactory, they were prescribed gutt. chloramphenicol without preservative twice daily and reassessed every two weeks for eight weeks. Another lens was fitted if the original lens was seen to have a poor fit or to develop surface deposition. At eight weeks the symptoms occurring in each group were assessed for the duration of the treatment period by the above criteria. As the subjective experience of pain is so variable between patients, a control group would be unhelpful; it was decided to compare each individual patient in a longitudinal fashion before and during treatment.

A consecutive prospective series of all patients with traumatic, as opposed to dystrophic, corneal abrasion presenting to the same department in the same period were studied. The size and position of
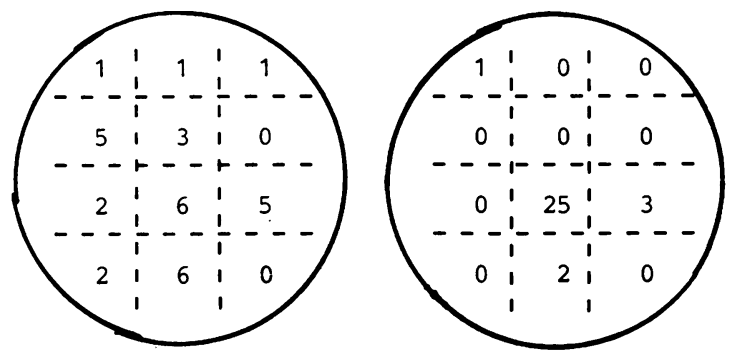

Fig. 1 Left: traumatic abrasion. Right: recurrent erosion.

the abrasion were recorded on a similar proforma to the previously mentioned.

\section{Results}

A total of 31 patients were seen; their mean age was 40 (range 20-60 years); 16 were male and 15 female. Symptoms had been occurring for an average of 14 months (range 3 months to 5 years). Twenty-one had a history of minor trauma to the affected eye. Of the total number of patients 24 were included in the trial of treatment; the others either declined to enter or failed to attend for follow-up. The general characteristics of those entering the trial are summarised in Table 1 and were seen to be similar in each group.

The position of recurrent erosions and abrasions recorded are shown in Fig. 1. A Hudson-Stahli line was found in $11(35 \%)$ eyes with recurrent erosion, and in all these cases the recurrent erosion and Hudson-Stahli line were in the same segment. In the 20 cases in which there was no detectable HudsonStahli line the erosion was at the usual site of the line in $17(85 \%)$ or in an immediately adjacent segment in two $(10 \%)$ and distant in only 1 case $(5 \%)$. Traumatic abrasions occurred all over the cornea and were not associated with the site of the Hudson-Stahli line.

Table 1 General characteristics of patients entering trial

\begin{tabular}{|c|c|c|c|c|c|c|c|c|c|c|}
\hline \multirow[t]{2}{*}{ Group } & \multirow[t]{2}{*}{ No. } & \multicolumn{2}{|c|}{ Age in years } & \multicolumn{2}{|c|}{ Sex } & \multicolumn{2}{|c|}{$\begin{array}{l}\text { Duration of symptoms } \\
\text { in months }\end{array}$} & \multicolumn{3}{|l|}{ Pain } \\
\hline & & Mean & Range & $M$ & $F$ & Mean & Range & Frequency & Duration & Severity \\
\hline 1 & 13 & 42 & $22-49$ & 8 & 5 & 7 & $3-15$ & 2 & 3 & $2 \cdot 3$ \\
\hline 2 & 11 & 45 & $29-60$ & 4 & 7 & 10 & $2-24$ & $2 \cdot 3$ & $2 \cdot 6$ & $2 \cdot 5$ \\
\hline
\end{tabular}

Table 2 Results of treatment

\begin{tabular}{llllll}
\hline Group & No & $\begin{array}{l}\text { Improved } \\
\text { symptoms } 3 \\
\text { scores }\end{array}$ & $\begin{array}{l}\text { Improved } \\
\text { on 2 } \\
\text { scores }\end{array}$ & $\begin{array}{l}\text { Improved } \\
\text { on 1 } \\
\text { score }\end{array}$ & $\begin{array}{l}\text { Same } \\
\text { on 3 } \\
\text { scores }\end{array}$ \\
\hline 1 & 10 & 1 & 2 & 0 & 0 \\
2 & 3 & 2 & 2 & 1 & 1 \\
\hline
\end{tabular}


Of the 10 patients who had endothelial specular photomicroscopy the appearances were normal in six; four showed essentially normal endothelium with blebbing, which was thought to be a response to the diagnostic contact lens applied. ${ }^{18}$

The results of treatment in the two groups are summarised in Table 2 . This refers to the pain only, subdivided into its three characteristics. In group 1, treated with topical agents, no complications other than further recurrent erosions were seen. In group 2 , in addition to poorer results of treatment, complications ensued in seven patients. Three had extensive epithelial loss under the contact lens similar to that occurring during recurrent erosion; in two this led to the lens being abandoned. In four patients the contact lens was frequently lost and had to be replaced many times.

\section{Discussion}

In this group of patients the usual site of recurrent erosion was seen to be very localised. Traumatic abrasions do not respect such boundaries. This fact, coupled with the frequent lack of a history of trauma, previous reports of unilateral trauma having bilateral erosion," and unilateral erosions having bilateral signs, ${ }^{24}$ suggests that trauma is unlikely to be the principal causative factor.

The previously unrecorded close positional association between the Hudson-Stahli line and recurrent erosion may imply either that the pathogenesis of the two is similar or that the Hudson-Stahli line is a causative factor in recurrent erosion. This may be a local epithelial abnormality. Alternatively it may be a localised expression of a generalised epithelial abnormality at this meeting point of epithelium migrating from the inferior and superior limbal palisades.

The specular appearances of the endothelium are normal. There is no morphological support for the theory that an endothelial abnormality is the underlying problem.

Medication in the treatment of group 1 was chosen as being the most innocuous of those previously suggested. The contact lens used in group 2 is one of the most frequently used at this hospital and provides a very high oxygen transmission. ${ }^{19}$ As the average duration of symptoms is many times the duration of treatment, it is likely that the alteration noted is attributable to the therapeutic effect rather than to the usual fluctuation of the disease.

The results in accordance with previous findings show that topical medications are very effective..$^{21}$ Until now therapeutic contact lenses have not been formally assessed in this condition, and they are here seen to be inferior in efficacy and accompanied by a high complication rate. Two previous reports of the use of therapeutic contact lenses in recurrent ulceration from all causes, not specifically MDF dystrophy, suggest a beneficial effect in $30-50 \%$, but neither was a formal trial. ${ }^{16}{ }^{17}$ The serious complications of therapeutic lenses such as corneal infection or vascularisation did not occur in our trial, but we have seen them in the use of therapeutic lenses for this condition. The absence of serious complications may be due to prophylactic antibiotics and close follow-up, but good fortune may have played a part. It is stressed that these complications may permanently impair vision, whereas the effect of recurrent erosion on vision is usually minimal and transient. It is suggested that the use of therapeutic contact lenses should be restricted to severely symptomatic cases in which close follow-up can be guaranteed.

We thank Mr M G Kerr Muir and Miss C Smyth for their assistance in preparation of this paper.

\section{References}

1 Keynon KR. Recurrent corneal erosion; pathogenesis and treatment. Int Ophthalmol Clin 1979; 19: 169-93.

2 Brown NA, Bron AJ. Recurrent erosion of the cornea. $\mathrm{Br} \mathrm{J}$ Ophthalmol 1976; 60: 84-96.

3 Chandler PA. Recurrent erosion of the cornea. Am J Ophthalmol 1945; 28: 355-67.

4 Brown NA, Bron AJ. Superficial lines and associated disorders of the cornea. Am J Ophthalmol 1976; 81: 34-50.

5 Bron AJ, Tripathi, RC. Cystic disorders of the corneal epithelium. I. Clinical aspects. Br J Ophthalmol 1973; 57: 361-73.

6 Laibson RP. Microcystic corneal dystrophy. Trans Am Ophthalmol Soc 1976; 74: 488-531.

7 Laibson PR, Krachmer JH. Familial occurrence of dot-map(microcystic) fingerprint dystrophy of the cornea. Invest Ophthalmol Visual Sci 1975; 14: 397-9.

8 Werblin TP, Hirst LW, Stark WJ, Maumenee IH. Prevalence of map-dot-fingerprint changes in the cornea. $\mathrm{Br} J$ Ophthalmol 1981; 65: 401-9.

9 Rodriegues MM, Fine PS, Laibson PR, Zimmerman LE. Disorders of the corneal epithelium: a clinico-pathological study of dot geographic and fingerprint patterns. Arch Ophthalmol 1974; 92: 475-82.

10 Tripathi RC, Bron AJ. Cystic disorders of the corneal epithelium: pathogenesis. Br J Ophthalmol 1973; 57: 376-90.

11 Flynn MA, Easterly DB. Bilateral recurrent erosion of the cornea. Am J Ophthalmol 1966; 62: 964-6.

12 Foulks GN. Treatment of recurrent corneal erosion with topical osmotic colloidal solutions. Ophthalmology 1981; 88: 801-3.

13 Lowe RF. Recurrent erosion of the cornea. Br J Ophthalmol 1979; 54: 805-9.

14 Trobe J, Laibson PR. Dystrophic changes in the anterior cornea. Arch Ophthalmol 1972; 87: 378-82.

15 Broderick JD, Dark J, Peace GW. Fingerprint dystrophy of the cornea. Arch Ophthalmol 1974; 92: 483-9.

16 Mobilia EF, Foster OD. Management of recurrent corneal erosions with ultrathin lens. Contact Intraoc Lens Med J 1978; 4: $25-9$.

17 Lemp P. Role of bandage lenses in recurrent erosion. Contact Intraoc Lens Med J 1977; 3: 28-32.

18 Buckley RJ. Transitory endothelial changes induced by soft contact lens. In: Henkind P, ed. Acta XXIV International Congress of Ophthalmology. Philadelphia: Lippincott, 1983.

19 Woodward EJ. Therapeutic contact lenses, form and materials. Contacto 1979; 23: 14-17. 